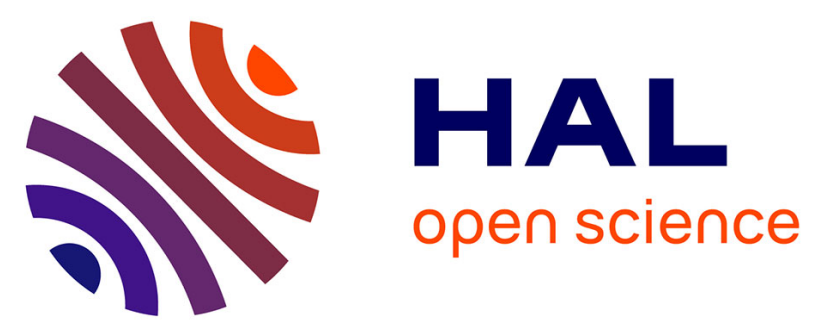

\title{
Thermo-Mechanical Modeling of Distortions Promoted during Cooling of Ti-6Al-4V Part Produced by Superplastic Forming
}

Maxime Rollin, Vincent Velay, Luc Penazzi, Thomas Pottier, Thierry

Sentenac, Laura Iranzo-Perez, Alain Dupuy, Gaël Khelifati

\section{To cite this version:}

Maxime Rollin, Vincent Velay, Luc Penazzi, Thomas Pottier, Thierry Sentenac, et al.. ThermoMechanical Modeling of Distortions Promoted during Cooling of Ti-6Al-4V Part Produced by Superplastic Forming. ICSAM 2015 - 12th International Conference on Superplasticity in Advanced Materials, Sep 2015, Tokyo, Japan. p. 196 - 201, 10.4028/www.scientific.net/MSF.838-839.196 . hal-01633694

\section{HAL Id: hal-01633694 https://hal.science/hal-01633694}

Submitted on 6 Jun 2018

HAL is a multi-disciplinary open access archive for the deposit and dissemination of scientific research documents, whether they are published or not. The documents may come from teaching and research institutions in France or abroad, or from public or private research centers.
L'archive ouverte pluridisciplinaire $\mathbf{H A L}$, est destinée au dépôt et à la diffusion de documents scientifiques de niveau recherche, publiés ou non, émanant des établissements d'enseignement et de recherche français ou étrangers, des laboratoires publics ou privés. 


\title{
Thermo-mechanical modeling of distortions promoted during cooling of Ti-6Al-4V part produced by superplastic forming
}

\author{
Maxime ROLLIN ${ }^{1,2, a *}$, Vincent VELAY ${ }^{1, b}{ }^{\text {Luc PENAZZI }}{ }^{1, c}$, Thomas POTTIER ${ }^{1, d}$, Thierry SENTENAC ${ }^{1, e}$, \\ Laura IRANZO-PEREZ ${ }^{2, f}$, Alain DUPUY ${ }^{2, g}$ and Gaël KHELIFATI ${ }^{2, h}$ \\ 1: Université de Toulouse; INSA, UPS, Mines Albi, ISAE; ICA (Institut Clément Ader), Albi, France \\ 2: AIRBUS (Toulouse, France) \\ amaxime.rollin@mines-albi.fr, ${ }^{b}$ vincent.velay@mines-albi.fr, ${ }^{9}$ luc.penazzi@mines-albi.fr, ${ }^{d}$ thomas.pottier@mines-albi.fr, \\ ethierry.sentenac@mines-albi.fr, ${ }^{\dagger}$ laura.iranzo-perez@mines-albi.fr, ${ }^{9}$ alain.a.dupuy@airbus.com, ${ }^{\text {h }}$ gael.khelifati@airbus.com
}

Keywords: Superplastic forming, Part Cooling, thermo-mechanical loadings, Residual stresses, Finite Element

\begin{abstract}
In AIRBUS, most of the complex shaped titanium fairing parts of pylon and air inlets are produced by superplastic forming (SPF). These parts are cooled down after forming to ease their extraction and increase the production rate, but AIRBUS wastes a lot of time to go back over the geometric defects generated by the cooling step. This paper investigates the simulations of the SPF, cooling and clipping of a part operations on Abaqus ${ }^{\circledR}$ Finite element software. The different steps of the global process impact the final distortions. SPF impacts the thickness and the microstructure/behavior of material, cooling impacts also the microstructure/behavior of material and promotes distortions through thermal stresses and finally, clipping relaxes the residual stresses of the cut part. An elastic-viscoplastic power law is used to model material behavior during SPF and a temperature dependent elastic perfectly plastic model for the cooling and clipping operations.
\end{abstract}

\section{Introduction}

SPF of parts at AIRBUS is carried out with different titanium alloys. The alloy considered in this paper is the Ti-6Al-4V. Its superplastic properties are well known [1], [2]. Indeed, many researcher have highlighted the fact that for couples of temperature and strain rates, associated with an equiaxed grain microstructure, the Ti-6Al-4V provides a very high elongation. This significant deformation occurs due to the superplastic deformation mechanisms of the grain boundary sliding and accommodation thereof [3]-[5]. These superplastic deformation mechanisms enables to maintain a stability of the microstructure during deformation. Therefore, SPF parts preserve good properties after forming, in particular for fatigue strength.

In order to increase production rates, the parts are cooled after forming. The cooling is performed inside the press by gas jet through nozzle covering the whole surface of the part. They are cooled up to a temperature low enough so as to extract the part without deforming the latter during the operation. Once extracted from the mold, it is then cooled to ambient temperature. To cool by gas jet induces inhomogeneous thermal stresses distributed on the surface of the workpiece, which moreover, have an inhomogeneous thickness distribution. The combination of these two phenomena causes the occurrence of plastic deformation and residual stresses, which produces improper final geometry once released after clipping the useful piece,.

In addition to these thermomechanical phenomena, there are also microstructure evolutions during cooling. The order of magnitude of gas jet cooling rates can promote metastable transformation of beta phase during cooling [6]. The Widmanstätten morphology of these microstructures has higher mechanical properties than classical lamellae morphology obtained by slow cooling [2].

The purpose of this study is to model the different stages of the production process of these parts in order to try to reproduce the influence of cooling strategy on their final geometry. The simulation has been made on Abaqus ${ }^{\circledR}$ finite element software. In this model, microstructure evolution 
phenomena related to fast temperature changes cited just above are not taken into account. Only the deformation phenomena related to the thermal stresses on the geometry of the workpiece and the evolution of yield stress as a function of temperature were taken into account.

\section{Model Description.}

This paper presents the modeling of forming, cooling and clipping operations of an air inlet part of A320 AIRBUS plane. The geometry of this part is represented in Figure 1.a through the mold geometry, and in Figure 1.b through the final part obtained after clipping operation.

a)

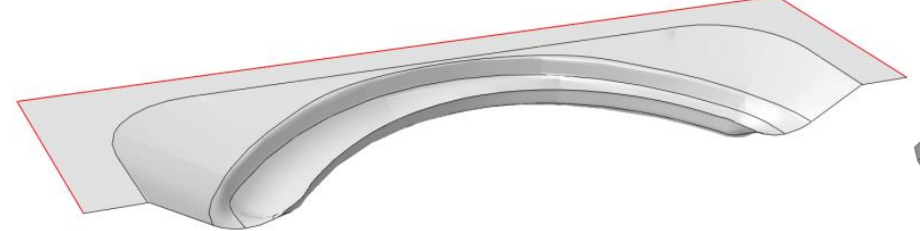

b)

Figure $1:$ a) CAO representation of the SPF mold (partial representation of the part for confidentiality issues); $b$ ) CAO of the final part obtain after clipping

The geometry of mold has been discredited with R3D4 discrete rigid elements. The SPF part has been respectively discredited with DS4 Heat transfer elements and S4R deformable shell element [7]. The different steps of the numerical procedure are defined in the next paragraph.

Multi-step modeling. The different steps included in this model are the SPF, the cooling and the clipping of the part:

- SPF step:

The forming step is modeled with Abaqus/Standard Visco step [7]. This integration procedure is used to obtain a transient static response in an analysis with time-dependent material behavior. The pressure cycle is computed during the simulation so that to respect a maximum plastic strain rate.

The SPF modeling is made separately and only the thickness field is transferred to the cooling simulation. This reduction comes from the hypothesis that the residual stress field at the end of forming is almost null [8], and that there is no hardening or microstructure evolution into the material model, only the geometry has to be transferred to cooling step modeling. A schematic of numerical procedure is represented Figure 2.

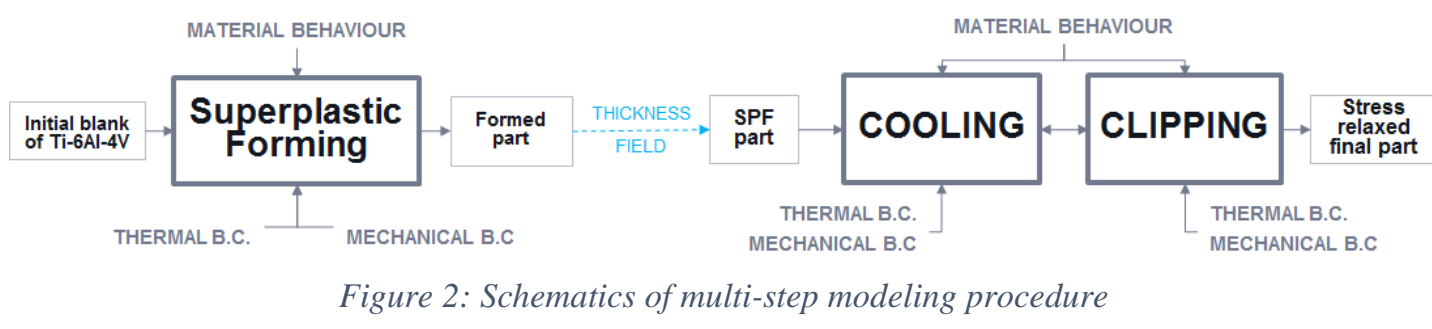

- COOLING step:

The cooling is divided in four different steps defined in Figure 3. The opening of the press corresponds to the heat transfers that happened during the opening of the press and the insertion of the extraction/cooling manipulator inside. The gas jet cooling corresponds to the activation of gas blowing. After a certain time, the extraction step is triggered. The extraction system takes the part out of the mold thanks to a frame on which the part is clamped (schematically represented on Figure 1.a by red lines). After extracting the part, it is cooled at ambient temperature up to complete cooling. In the model presented here, the extraction step has been suppressed. The part passes from gas jet cooling to ambient cooling without the transient step between both. 


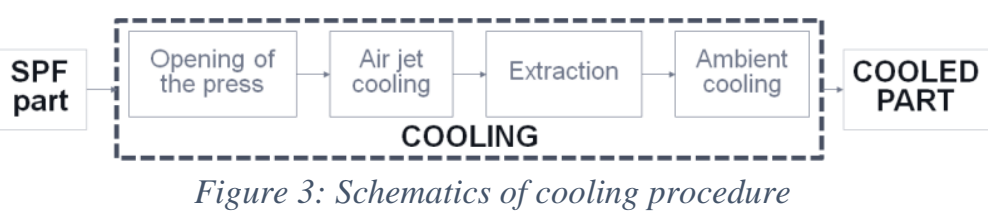

- CLIPPING operation

The clipping operation is made by laser cutting. In the simulation it is virtually made by element removing in a static stress-displacement analysis. It excludes local phenomena during laser cutting.

Material model. The material behavior of Ti-6Al-4V titanium alloy is particularly difficult to model as it have numerous deformation modes on the temperature and strain rate range on our process. Yet, it is possible to split the problem into two different phases in matter of material behavior: the superplastic forming part, and the cooling.

- SPF step

Bellet has shown [3] that a viscoplastic power law as Norton Hoff law (see Equation 1) enables to model SPF, where $\sigma_{0}$ is the yield stress, $K$ the consistency of material and $\dot{\bar{\varepsilon}}_{p l}$ the equivalent plastic strain rate. Semiatin \& al. and Gosh \& Hamilton have shown [1], [2] that the strain rate sensitivity parameter $\mathrm{m}$ of Ti-6Al-4V is dependent on temperature $\mathrm{T}$, plastic strain $\varepsilon$, plastic strain rate $\dot{\varepsilon}_{p l}$ and grain size $d$. The process of forming at AIRBUS is made for particular small range of temperature and strain rate, during what, both parameters are targeted on optimal values. Moreover, SPF parts do not exceed fifty percent of deformation. In these conditions, the hypothesis has been made that the strain rate sensitivity parameter $m$ remains constant during forming.

$$
\begin{aligned}
& \sigma_{0}=K \dot{\bar{\varepsilon}}_{p l}^{m} \\
& m=\frac{\partial \ln \left(\sigma_{0}\right)}{\partial \ln \left(\dot{\varepsilon}_{p l}\right)}
\end{aligned}
$$

- Cooling and Clipping step

During cooling, the evolution of temperature mainly influences the deformation mechanisms. The strain and strain rate are very low because they are promoted by expansion. The order of magnitude of maximum strain rate under maximum cooling rate undergone is about $\dot{\varepsilon}=10^{-5} \mathrm{~s}^{-1}$. That is why in a first approximation, an elastic perfectly plastic model evolving with temperature has been chosen.

Thermal loadings. There is different kind of heat transfer during the three steps of cooling. There are schematically described Figure 4.The different boundary equations of conduction, radiation and convection heat transfers are respectively presented in Equation 3-5, where $\mathrm{T}$ is the temperature of the part at the boundary, $\mathrm{k}$ is the conductivity of the material, $\phi_{c o n d}, \phi_{\text {rad }}$ and $\phi_{\text {conv }}$ are respectively the conduction, the radiation and the convection flux, $\lambda$ is the thermal conductance (or the inverse of the thermal contact resistance), $T_{\text {mold }}$ is the mold temperature, $\epsilon$ is the emissivity of the part, $\sigma_{r}$ the Stephan Boltzmann constant, $T_{\text {lim }}$ is the limit temperature for radiation, $\mathrm{h}$ the convection coefficient and $T_{g a s}$ is the temperature of gas.

- Press opening:

At the beginning of this step, the system is considered at a constant temperature of SPF. There are conduction convection and radiation heat transfers. The limit temperatures $T_{\text {mold }}, T_{\text {lim }}$ and $T_{\text {air }}$ of these equations evolve during the step. 
a)

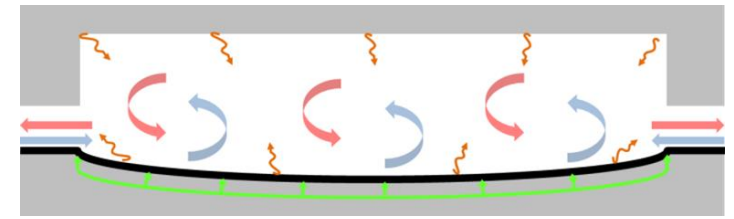

c)

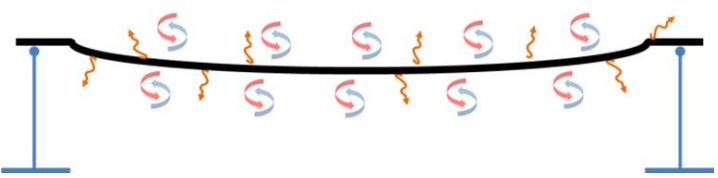

d)

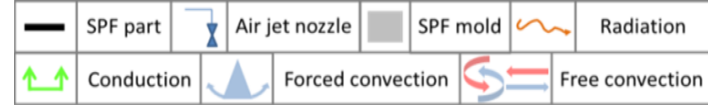

Figure 4: Description of heat transfer during a) The opening of the press, b) The gas jet cooling, c) the Ambient cooling, d) Caption

- Gas jet cooling

There are also conduction and radiation (with different limit temperatures than the previous step). Concerning convection, the definition of $\mathrm{h}$ coefficient is not uniform, and the limit temperature is constant at gas blown temperature. Mohanty \& Tawfek have established [9] Equation 6 the evolution of $\mathrm{h}$ in the case of heat transfer due to a round jet impinging on a flat surface, where $\mathrm{r}$ is the radius around the projected center of a nozzle vertically on the surface of the part, $h_{0}, h_{s f}$ and $\mathrm{k}$ are constants. $h_{s f}$ represents the "semi-forced" convection promoted by gas flows around nozzles. This model has been characterized in the process conditions.

- Ambient cooling

Convection and radiation occur with limits temperatures equal to ambient temperatures.

$$
\begin{aligned}
& k \nabla T=\phi_{\text {cond }}=\lambda\left(T_{\text {mold }}-T\right) \\
& k \nabla T=\phi_{\text {rad }}=\epsilon \sigma_{r}\left(T_{\text {lim }}{ }^{4}-T^{4}\right) \\
& k \nabla T=\phi_{c o n v}=h\left(T_{\text {gas }}-T\right) \\
& h(r)=\left(h_{0}-h_{s f}\right) \cdot e^{-k \cdot r^{2}}+h_{s f}
\end{aligned}
$$

Model parameters. The parameters that have been used for the different models described above are presented in Table 1 and Table 2.

\begin{tabular}{|c|c|c|c|c|c|c|c|}
\hline \multicolumn{7}{|c|}{ Material Parameter } & \multicolumn{6}{|c|}{ Thermal parameters } \\
\hline $\begin{array}{c}\mathrm{K} \\
(\mathrm{MPa})\end{array}$ & $\mathrm{m}$ & $\begin{array}{c}\lambda \\
\left(W \cdot m^{-2} \cdot K^{-1}\right)\end{array}$ & $\epsilon$ & $\begin{array}{c}h \\
\left(W \cdot m m^{-2} \cdot K^{-1}\right)\end{array}$ & $\begin{array}{c}h_{0} \\
\left(W \cdot m m^{-2} \cdot K^{-1}\right)\end{array}$ & $\begin{array}{c}h_{s f} \\
\left(W \cdot m m^{-2} \cdot K^{-1}\right)\end{array}$ & $\begin{array}{c}k \\
\left(m m^{-2}\right)\end{array}$ \\
\hline 3000 & 0.75 & $* 1$ & $* 1$ & $0.02[9]$ & $0 . *^{2}$ & $0.0 *^{* 2}$ & $1.10^{-4} *^{2}$ \\
\hline
\end{tabular}

Table 1: material and thermal models parameters; $*^{1}:$ confidential data, $*^{2}:$ Forced cooling measurement

\begin{tabular}{|c|c|c|c|c|c|c|c|c|c|c|c|c|}
\hline $\mathrm{T}\left({ }^{\circ} \mathrm{C}\right)$ & 25 & 100 & 200 & 300 & 400 & 500 & 600 & 700 & 750 & 800 & 850 & 900 \\
\hline$\sigma_{0}(\mathrm{MPa})$ & 950 & 930 & 900 & 850 & 800 & 700 & 500 & 200 & 90 & 45 & 20 & 10 \\
\hline
\end{tabular}

Table 2: evolution of yield stress as a function of temperature (Cooling material model); extrapolation of data from internal and external sources [10], [11]

\section{Results}

Cooling strategies. Three distinct strategies of cooling have been tested in the model, in order to test the impact of temperature distribution and its evolution during cooling. The temperatures or heat transfers imposed to the part are not all industrially workable and/or used, but they are a mean to understand how does the temperature evolution is important.

- "Free" cooling: this strategy consists in letting the part cooling down slowly on the mold up to ambient temperature at the exterior of the press (in "ambient cooling" thermal loadings condition with conduction to the mold whose temperature decrease linearly to ambient). 
- "Homogeneous" cooling: this strategy consists in applying the thermal loadings described above, but replacing the forced convection coefficient defined by Equation 6 with a constant uniform value $h_{0}$. This forced convection has been applied on the whole surface of the part.

- "Exterior" cooling: this strategy consists in applying the thermal loadings described above. The position of gas jet nozzles is represented on Figure 5.

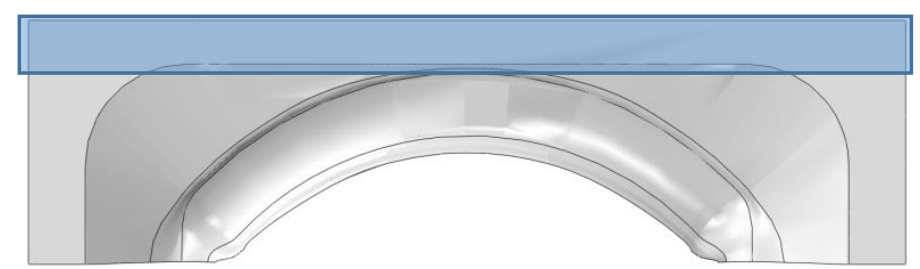

Figure 5: Schematic representation of nozzle impingement area (blue area) for "Exterior" cooling

Impact of cooling strategy. The easiest way to measure the impact of cooling strategy on final distortions is to quantify the distortions themselves. The deformed meshes after clipping of the different cooling strategies presented previously have been superposed in Figure 6-a. The Figure 6$\mathrm{b}$ represents a cutting view on the node belonging to mold that has been used to superpose the deformed meshes. Indeed the final meshes before clipping have not been deformed the same way, and geometry to be clipped has undergone rotations and translations in addition of inelastic deformations.

a)

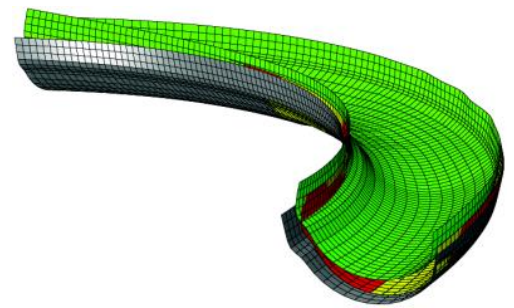

b)

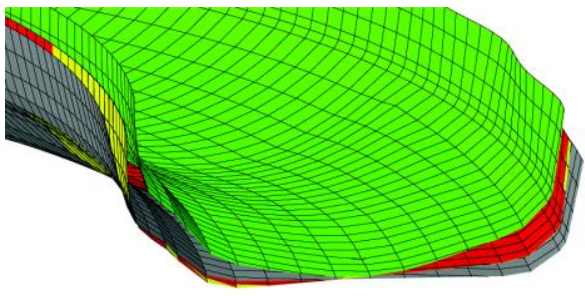

Figure 6: Mesh superposition of different cooling strategies (Grey:mold; Red:"homogeneous" ; purple:"ext" ; green:"free") ; a) global view, b) Cut view on reference node

The Figure 7-a represents the impact of cooling strategy on the average and the standard deviation of the norm of displacement of clipped nodes compared to mold nodes. The Figure 7-b presents the same kind of results, but compared to "homogeneous" cooling strategy. These figures enable to compare the impact of the cooling strategies. To analyze these results, it is important to remind the fundamental differences between the three different strategies.

a)

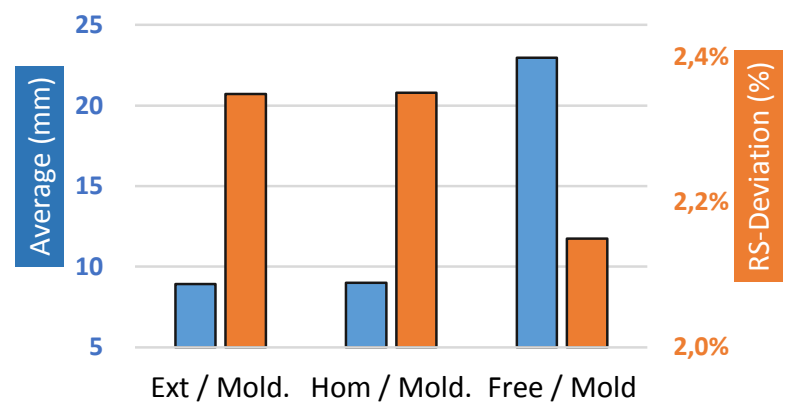

b)

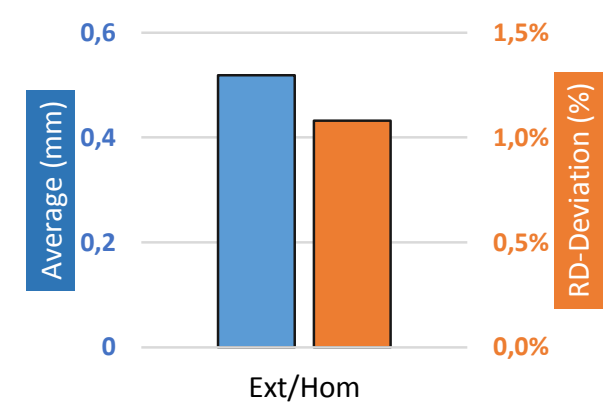

Figure 7: Impact of cooling strategies on Distortions (blue: average norm of displacement vector; yellow: Standard deviation); a) from mold initial position b) from "homogeneous" cooling deformed position

The exterior and homogeneous strategies are rather closed, except concerning the location of forced cooling. On the contrary, the free cooling strategy does not contain force cooling, and the mold and 
lower surface of the part are in contact all along cooling. The Figure 7-a shows firstly that the distortions are not the same according to the different cooling strategies. Secondly, the results for each strategies are far from mold geometry (more than $8 \mathrm{~mm}$ on average), what is not as far in reality (whatever the cooling strategy). The Figure 7-b still shows that there is a large difference of impact on distortions between "free" and "homogeneous" cooling strategies. On the contrary, the "exterior" and "homogeneous" cooling strategies have almost no differences.

Conclusions. A numerical procedure for modeling forming, cooling and clipping operations of SPF part manufacturing has been established. Several strong hypotheses like material behavior but also boundary conditions have been made. These hypotheses lead to acceptable results, but not consistent with reality. The previous results expose several issues on this numerical model:

- The fact the two strategies of forced convection give approximately the same results says that either the gradients of temperature in the part have no impact in comparison of the geometry of the part that imposes the deformation through its expansion and the boundary conditions; or, the boundary condition of clamping of the part at the border over constrains the part whereas in reality the frame on which the part is attached deforms.

- The non-sensitivity of material model to strain rate (indirectly to cooling rate) could be also a reason of results commented just above.

- The comparison of homogeneous forced convection with complete free cooling shows that inside the complexity of the problem, the mold conduction phenomena (related to gradient of temperature in the thickness of part) have an impact on distortions.

Outcomes. Some improvements have to be done to enable better results. The material needs to be strain rate sensitive in order to transcribe the cooling rate effects on material. Moreover, the frame on which the part is attached need to be modeled to see how it supports the part loading and it limits part deformations. An important characterization needs to be done for every model parameters coming from hypotheses (like friction coefficient, emissivity, etc.). Once the model will behave consistently with AIRBUS process, some cooling experiments on SPF presses will be made to compare and fit the model with the reality.

\section{References}

[1] A. K. Ghosh and C. H. Hamilton, "Mechanical behavior and hardening characteristics of a superplastic Ti-6AI-4V alloy," Metall. Trans. A, vol. 10, no. 6, pp. 699-706, Jun. 1979.

[2] S. L. Semiatin, V. Seetharaman, and I. Weiss, "Hot workability of titanium and titanium aluminide alloys - an overview," Mater. Sci. Eng. A, vol. 243, no. 1-2, pp. 1-24, Mar. 1998.

[3] M. Bellet, "Modelisation numerique du formage superplastique de toles," EMP, 1988.

[4] T. Langdon, "An Analysis of Flow Mechanisms in High Temperature Creep and Superplasticity." .

[5] B. Babu, "Physically Based Model for Plasticity and Creep of Ti6A14V," Licenciate thesis, 2008.

[6] K. Kubiak and J. Sieniawski, "Development of the microstructure and fatigue strength of two phase titanium alloys in the processes of forging and heat treatment," J. Mater. Process. Technol., vol. 78, no. 1-3, pp. 117-121, Jun. 1998.

[7] D. S. Simulia, Ed., "Abaqus/Standard Users Manual.” Dassault Systèmes.

[8] Superplastic Forming of Advanced Metallic Materials. Elsevier, 2011, pp. xiii-xiv.

[9] "Convective Heat Transfer." [Online]. Available: http://www.engineeringtoolbox.com/convectiveheat-transfer-d_430.html. [Accessed: 22-Apr-2015].

[10] M. Vanderhasten, L. Rabet, and B. Verlinden, "Ti-6Al-4V: Deformation map and modelisation of tensile behaviour," Mater. Des., vol. 29, no. 6, pp. 1090-1098, Jan. 2008.

[11] G. A. Salishchev, S. V. Zherebtsov, S. Malysheva, A. Smyslov, E. Saphin, and N. Izmaylova, "Mechanical Properties of Ti-6Al-4V Titanium Alloy with Submicrocrystalline Structure Produced by Multiaxial Forging," in Materials Science Forum, 2008, vol. 584-586, pp. 783-788. 